\title{
Moving Toward "Mega-choice”: The Evolution of Access Technologies in Special Collections
}

\section{Introduction}

Recent technological changes have brought questions of access to the forefront of the special collections and archival professions and transformed the process by which access is attained. Librarians and archivists are increasingly called to make far-reaching decisions about the evolving shape of both in-person and remote access to collections, and newcomers to the profession, in particular, can benefit from better understanding the adoption, evolution, and disruption of older access technologies. While contemplating RBM's call for submissions on the theme of "the digital vs. the physical," the authors found themselves reading extensively on the subject of past access systems. Hoping to provide the kind of synthesized overview that the authors wish they had read as graduate students or early-career librarians, this article seeks to give a broad outline of how the evolution of access technologies has created frameworks that shape users' understanding and interpretation of historical information.

Since the late eighteenth century, archivists and librarians have moved toward a paradigm of fostering universal access to special collections materials. The adoption of access technologies and the ways they structure researchers' interactions with archival and rare materials has had a significant, if seldom acknowledged, impact on research methodologies and knowledge creation. At a basic level, access technologies are tools that facilitate connections between users and artifacts, whether through contact with physical material or its informational content. The authors suggest separating access technologies into three categories, each with a distinct purpose:

Discovery tools are technologies that facilitate or mediate the process of users learning that materials of interest exist, such as catalogs or finding aids;

Reproduction tools are technologies that facilitate physical or informational access to the content through duplication, such as published editions of manuscript collections or digital facsimiles; and

Promotional tools are technologies that connect users to materials they did not yet know that they needed through outreach and marketing. 
Though a central premise of this article is that these three access technologies have distinct historical trajectories, in today's digital environment they often operate within a single multifaceted platform.

The broad goals of technology use in special collections have remained surprisingly constant. However, this proposed taxonomy serves to highlight the ways in which technology — and especially the move toward the digital realm-has transformed the manner in which those goals are accomplished. By redefining the relationship between users and archival information, this transformation has dramatically expanded the audience for archival and rare materials. Looking at discovery tools as a group highlights the concrete ways in which decisions about description affect the use and accessibility of materials, as well as the potential for institutional cooperation in facilitating access. Reproduction tools, as a category, help to focus attention on the trade-offs past professionals have made in balancing preservation with access, and deciding upon appropriate degrees of content curation. Finally, identifying promotional tools allows librarians to confront the opportunities and challenges of marketing in digital landscapes flooded with information. Overall, this framework opens a window into the historical background of contemporary struggles regarding access that may provide relevant precedents for access technologies today.

\section{Discovery Tools}

The first step in providing access is enabling users to discover the existence of materials. Tools like catalogs and finding aids play an important role in making users independent. Instead of relying entirely on a reference interview, researchers are able to search and identify materials relevant to their research on their own terms. Thus, the initial relationship between user and object is mediated not through direct contact with archivists and librarians, but through discovery tool interfaces and the metadata that staff make available in item or collection records.

Catalogs in the form of lists have a lengthy history, from the clay tablets of Babylonian libraries to the chronological calendars of the nineteenth century. Likewise, the circulation of enumerative bibliographies dates back at least to the sixteenth century. Crucial changes in both bibliography and the production of catalogs occurred in the nineteenth century, including the expectation that bibliographers would physically examine books, ${ }^{1}$ and increasing standardization of print cataloging, particularly following Charles Cutter's 1876 Rules for a Printed Dictionary Catalog. In the case of European government archives, pioneers began developing

1. D.W. Krummel, "The Dialectics of Enumerative Bibliography: Observations on the Historical Study of the Practices of Citation and Compilation,” Library Quarterly 58.3 (July 1988): $240-41$. 
systems based on respect des fonds at this time, but the description of archives and manuscripts tended to remain idiosyncratic to individual repositories well into the twentieth century. ${ }^{2}$

Since World War II, descriptive practices for print and archival materials have become increasingly standardized and integrated into systems of discovery that bridge the library/archive divide. Over the past seventy years, four distinct but related developments have transformed the process of discovery in archives and special collections: national union catalogs, bibliographic records, online public access catalogs, and standardized finding aids.

The development of the National Union Catalog of Pre-1956 Imprints (NUC) and the National Union Catalog of Manuscript Collections (NUCMC) in the 1950 s and 1960s provided nationally scoped, cross-institutional tools for discovery. Published from 1968 to 1981, NUC Pre-1956 was a cooperative effort between the Library of Congress and the American Library Association to produce a main entry catalog recording pre-1956 publications held in American and Canadian libraries. ${ }^{3}$ To achieve this ambitious task, more than 25 editors prepared almost 20,000 cards a week for 14 years. ${ }^{4}$ Although usually mediated by librarians, NUC Pre-1956 expanded access by providing a record of where desired print materials were held, facilitating research travel and interlibrary loan requests.

NUC Pre-1956 quantitatively expanded discovery opportunities by drawing on wellestablished practices of shared cataloging. On the other hand, while NUCMC's content was undoubtedly important, its most fundamental contribution was its systemization of collection-level description. ${ }^{5}$ Although conceived earlier, NUCMC became a reality when the Library of Congress received a 1958 grant from the Council on Library Resources. Data sheets requesting specific collection-level information were sent to repositories, and the results were collated into standardized registry entries. ${ }^{6}$ These data sheets can be seen as precursors of Dublin Core or EAD. Their content

2. Harriet Ostroff, "From Clay Tablets to MARC AMC: The Past, Present, and Future of Cataloging Manuscript and Archival Collections," Provenance 4 (Fall 1986): 1-2. Standardization of print cataloging was driven by "the ready availability of LC printed cards, the opportunities for shared cataloging, and the existence of a national union catalog for books," for which archival counterparts did not exist in the early twentieth century.

3. "Information for Researchers Using the Library of Congress," Library of Congress, available online at www.loc.gov/rr/main/inforeas/union.html [accessed 17 October 2015].

4. William J. Walsh, "The Library of Congress and The National Union Catalog," in In Celebration: The National Union Catalog, Pre-1956 Imprints, ed. John Y. Cole (Washington: Library of Congress, 1981), 10.

5. Terry Abraham, "NUCMC and the Local Repository," American Archivist 40.1 (Jan. 1977): 33.

6. Ibid.," 31-42; "NUCMC History Timeline: 1947-present," National Union Catalog of Manuscript Collections, Library of Congress, available online at www.loc.gov/coll/nucmc/timeline.html [accessed 22 October 2014]. 
was specific to the repository and collection, but the kind and format of information was consistent across records. Despite its many benefits, the value of standardization was considerably debated. In particular, the influence of library practices on NUCMC's design led to concerns that converting information about archival material into a book-centered format ignored crucial aspects of archival use. ${ }^{7}$

During the 1970 s and 1980s, archives were increasingly integrated into librarywide discovery tools. Libraries had begun sharing MARC records on magnetic tape in the 1970s, but early attempts to implement state surveys of archives had limited success. ${ }^{8}$ Formed in 1977, the National Information Systems Task Force (NISTF) of the Society of American Archivists recommended developing a technical standard for exchanging data, ultimately leading to MARC-AMC, ${ }^{9}$ which facilitated the inclusion of archival records in existing bibliographic networks. ${ }^{10}$

Participation in bibliographic utilities using MARC records offered integrated access to information, regardless of format or location. Advocates argued that wider access to descriptive records would open archives to new audiences, ${ }^{11}$ but creating usable computerized catalogs required trade-offs. Inconsistent use of certain fields, selection of thesauri, and the lack of indexing inhibited discovery. ${ }^{12}$ Furthermore, users frequently misunderstood and misused the records they retrieved. For example, someone seeking data on rainfall might mistakenly request the archival records of a weather bureau, when they would be better served by an almanac. ${ }^{13}$

7. Richard C. Berner, "Archivists, Librarians, and the National Union Catalog of Manuscript Collections," American Archivist 27:3 (July 1964): 403-05.

8. Libraries participating in such ventures generally saw an ongoing benefit from copy cataloging; but archives, handling primarily unique materials, did not have similar incentives.

9. The Society of American Archivists (SAA) officially adopted MARC-AMC in 1981. Along with other special MARC formats, it was merged into USMARC in the mid-1990s. USMARC itself was later replaced by MARC21. "Marc Standards: MARC FAQ," Library of Congress, available online at www.loc. gov/marc/ [accessed 23 September 2015]. For a broad history of archival descriptive standards from the 1980s-2010s (and an argument for moving toward alignment with international archive standards), see Stephen L. Hensen et al., "Thirty Years On: SAA and Descriptive Standards," American Archivist 74, supplement 1 (Jan. 2011): 1-36.

10. David Bearman, "Archival and Bibliographic Information Networks," Journal of Library Administration 7.2/3 (Summer/Fall 1986): 100-05.

11. Robert P. Spindler and Richard Pearce-Moses, "Does AMC Mean 'Archives Made Confusing"? Patron Understanding of USMARC AMC Catalog Records," American Archivist 56.2 (Spring 1993): 330-41, available online at http:/ / archivists.metapress.com/content/y258x6655x047415/ fulltext.pdf [accessed 17 September 2015].

12. Avra Michelson, "Description and Reference in the Age of Automation," American Archivist 50.2 (Spring 1987): 194. Michelson notes that, in a study asking respondents to select indexing terms based on the description of a family collection, 21 repositories assigned 162 access points, with no single term being selected by every repository.

13. Spindler and Pearce-Moses, "Does AMC Mean 'Archives Made Confusing'?" Obviously the problem of not recognizing the kind of document being described was a problem that users of card catalogs also faced. However, Spindler and Pearce-Moses argue that the introduction of electronic systems exacerbated it. 
Unfamiliarity with computer technology also posed a barrier to the use of early electronic catalogs. ${ }^{14}$

By 1990, many institutions had replaced card catalogs with electronic versions, and pioneers were already moving toward remote access, with more than fifty catalogs available online "at no charge to the end-user." ${ }^{15}$ Howard Pasternack's 1990 RBML article described the John Hay Library’s efforts to add its records to Brown University's online catalog and notes that several other institutions were engaged in similar projects. Pasternack mentioned that many standard features of today's online catalogs - such as the ability to limit searches by collection, format, genre, or location-were uncommon at that time. He urged special collections staff to articulate the need for such features to vendors and systems staff. ${ }^{16}$ A 1993 survey conducted by the RBMS Bibliographic Standards Committee revealed continued frustration with such limitations, especially the lack of indexing for key fields. ${ }^{17}$

Over the course of the 1990s, online public access catalogs offered greater independence to users, who relied less heavily on staff and on-site discovery tools to locate materials. Writing in 1986, David Bearman already envisioned the digitization projects of the twenty-first century, predicting a future online database that would combine catalog records with digital surrogates. ${ }^{18}$ While freeing researchers from direct dependence on staff, these developments meant that researchers only had access to as much information about a collection or item as could be included in the online record unless they specifically sought contact with staff, something undergraduates and new researchers are often hesitant to do. This hesitancy has only grown more marked with the intervening years, as inexperienced researchers often assume that anything that can be found will be found online. While more users receive some information, they do not receive full information-and not necessarily the most relevant information.

14. Alex A. Koohang, "Effects of Age, Gender, College Status and Computer Experience on Attitudes Towards Library Computer Systems," Library and Information Science Research 8 (Oct.-Dec. 1986): 34955; Alex A. Koohang and David M. Byrd, "A Study of Attitudes Toward the Usefulness of the Library Computer System and Selected Variables: A Further Study," Library and Information Science Research 9 (April-June 1987): 105-11.

15. Howard Pasternack, "Online Catalogs and the Retrospective Conversion of Special Collections," RBML 5.2 (Fall 1990): 71-76.

16. Ibid., 71-73.

17. Henry Raine and Laura Stalker, "Rare Book Records in Online Systems," Rare Books and Manuscripts Librarianship 11.2 (Fall 1996): 103-06. For example, MARC fields such as 655/755 could describe "provenance, binding, and aspects of physical production," most catalogs used by respondents did not index those fields, indexed only one, or merged them with other fields, thereby significantly limiting researchers' ability to make effective use of the available information in their discovery efforts.

18. David Bearman, "Archive and Manuscript Control with Bibliographic Utilities: Challenges and Opportunities," American Archivist 52 (Winter 1989): 38. 
As MARC records and the integration of special collections into general library catalogs became common, finding aids also moved toward standardization and shared data. In the United States, archival finding aids-the inventories and registers that document context, structure, and content-developed through interaction between the historical manuscripts and public archives traditions. ${ }^{19}$ The former tended to prioritize arrangement and access by topic, chronology, and geography, while the latter privileged provenance and original order. Although the public archives perspective became more dominant in the twentieth century, most institutions embraced a hybrid system with card catalog records providing collection-level access and finding aids offering detailed information. ${ }^{20}$

In the 1970s, the Society of American Archivists (SAA) actively encouraged standardizing archival description. Finding aids were increasingly organized into biography, scope and content, series, and container list. ${ }^{21}$ In the move from in-house documents mediated through a researcher-archivist encounter, to unmediated, online documents, these standardized fields served as guideposts. In the 1990s, the Berkeley Finding Aid Project developed Encoded Archival Description (EAD) — a data structure standard for encoding finding aids on the Internet. ${ }^{22} \mathrm{EAD}$ also facilitated the creation of cross-institutional search interfaces, making it possible for academic and nonacademic historians to conduct broad and deep searches for archival materials. However, archivists preparing these documents continued to assume background knowledge of genre conventions and archival descriptive practices. ${ }^{23}$ Users from new audiences face difficulties interpreting finding aids and making the jump from discovery to use of archival resources.

In the last half-century, discovery tools have transformed the research encounter from one in which scholarly researchers relied heavily upon archivists and librarians to guide them to relevant materials to one in which discovery happens almost

19. Ernst Posner, Archives and the Public Interest: Selected Essays by Ernst Posner, ed. Ken Munden (Chicago: Society of American Archivists, 2006): 30-31. Although archives as gathering points for records date back to antiquity, archives as centralized governmental institutions with a mandate for public access have primarily developed since the French Revolution. Throughout much of the nineteenth century, however, even government archives operated much like the historical manuscript collections of libraries, placing a low value on "modern" governmental papers and creating access points based on the anticipated needs of historical scholars. In the mid-nineteenth century, the principle of respect des fonds gained traction and government archives' emphasis on provenance and original order eventually came to influence library manuscript collections, in its own turn. For more detailed historical analysis of archival practices, see Richard C. Berner, Archival Theory and Practice in the United States: A Historical Analysis (Seattle: University of Washington Press, 1983).

20. C. Trace and A. Dillon, "The Evolution of the Finding Aid in the United States: From Physical to Digital Document Genre," Archival Science 12.4 (Dec. 2012): 504-06, 513.

21. Ibid.," 508.

22. For a detailed history of EAD’s development, see Daniel V. Pitti, "Encoded Archival Description: The Development of an Encoding Standard for Archival Finding Aids," American Archivist 60.3 (Summer 1997): 268-83.

23. Trace and Dillon, “The Evolution of the Finding aid in the United States," 504, 513. 
accidentally, as a student's Google search leads to an EAD finding aid at a repository halfway around the world. This democratization of access is an incredible accomplishment, made possible by slow and often hard-fought agreement about standardized terminology, practices, and presentation. However, standardization has not come without casualties. Researchers must rely on their own search expertise navigating catalogs, finding aid databases, and search engines. The tools for discovery are now almost universally available, but there is still work to be done finessing these tools to minimize their learning curves, to make the limitations of searching more transparent, and to provide both the tools and skills needed to effectively assess search results without succumbing to information overload.

For example, current "next generation" catalogs are somewhat successful in simplifying the user experience by offering federated searching and faceted navigation. However, this very simplification tends to make the back-end process more opaque, making it harder for users to understand why they received the results they did. Additionally, because facets are derived from bibliographic information in the traditional catalog, they remain limited to often unintuitive subject terms. While the opportunity to colloquially tag items of interest could have benefits, achieving a critical mass of user participation remains elusive. Furthermore, there is ongoing tension between the need to offer personalized tools for discovery while at the same time protecting users' privacy.

\section{Reproduction Tools}

The history of reproductions, like discovery tools, can be traced to antiquity, when scribes reproduced manuscript scrolls and codices. The age of mechanical reproduction, however, marked a defining change in archival access for a wider audience, as documentary editors published manuscripts in book form. The development of manuscript publishing in the United States as a method for expanding access to primary sources began in the 1790s with Jeremy Belknap and Ebenezer Hazard's 1792 Historical Collections, Consisting of State Papers, and Other Authentic Documents, Intended as Materials for an History of the United States of America, widely considered the first example in the United States of an editor and publisher assembling, editing, and printing documents held in private hands or government archives. Their project served as a harbinger of historical documentary editing projects in the nineteenth century that used print publication to provide access to private manuscripts and government documents. ${ }^{24}$ Hazard, Belknap, and many later editors also promoted publication as a preservation technology that would "increase the copies" to mitigate against disaster and loss. ${ }^{25}$

24. Randall Jimerson, "Documents and Archives in Early America," Archivaria 60 (Fall 2005): 235.

25. This concept of a preservation-access duality is a commonly used justification across all access technologies. 
In 1833, the U.S. Congress approved funding to publish selected historical records of the U.S. government. The following year, Congress allocated funds to acquire the papers of many of the founding figures of the Republic, and a number of published editions appeared over the next two decades, including the papers of James Madison (1837), Alexander Hamilton (1848), and Thomas Jefferson (1848). By the beginning of the twentieth century, it was hard to overlook the revolution in access initiated by manuscript publishing. Relying on the distribution networks of the publishing industry (like libraries, bookshops, and catalogs), manuscript publishing took advantage of existing access points. The previous access model of one user to one manuscript transformed to allow a comparatively unlimited number of users and access points. Manuscript publishing removed many of the previous barriers to archival access for the reading public.

Founded in 1935, the National Historical Publications Commission (NHPC) funded many manuscript publishing projects. By providing a reliable funding stream, it established manuscript publishing as the de facto access technology for archival records in the postwar period. ${ }^{26}$ With funding came accountability and standards developed by the burgeoning profession of editors and historians. By the second half of the twentieth century, manuscript publishing was focused on achieving an enhanced text, rather than expanding access. Editors increasingly stressed the importance of determining an authoritative version of a text, eliminating inconsistencies and errors in transcription, and providing the proper context for understanding historical manuscripts. ${ }^{27}$

Documentary editors' shift toward textual criticism was influenced by the development of microfilm. Beginning in the 1920s, it became the preferred technology for access and preservation. Though initially used to reproduce voluminous bank records, archivists recognized that the technology offered advantages over manuscript publishing as an economical preservation technology. The first major project to use microfilm for manuscripts, John D. Rockefeller's Project A, began in 1927, microfilming manuscripts held in European and Mexican institutions pertaining to the history of the United States. Microfilm continued to be viewed as a transformative access technology for special collections throughout much of the 1930s and 1940s, with several high-profile projects bolstering this perspective..$^{28}$ Early adopt-

26. Mary A. Giunta, “The NHPRC: Its Influence on Documentary Editing, 1964-1984,” American Archivist 49.2 (Spring 1986): 134-41.

27. David J. Nordloh, “The 'Perfect' Text: The Editor Speaks for the Author," Newsletter of the Association for Documentary Editing 2.2 (1980): 1-3.

28. Examples include the publication of the Manual on Methods of Reproducing Research Materials in 1936, the activities of the Historical Records Survey during the 1930s using microfilm to reproduce state and local records, the U.S. Commerce's 1939 report determining that microfilm is "suitable for permanent records," and the growth of the Center for American Documentation (and the center's journal American Documentation) as the primary advocate for the technology. 
ers, such as the Center for American Documentation, were vocal in their advocacy of the new technology, but there were still significant barriers to microfilm as an access technology. Cost, staff time and expertise, and equipment all limited adoption. Many archivists were intrigued by the possibilities of the technology, which could allow the circulation of entire collections throughout a network of repositories, instead of edited selections of small numbers of documents. In contrast to manuscript publishing, where the user trusted the editor to provide a representative selection from a larger body of archival documents, microfilm offered users the opportunity to become both researcher and editor.

Microfilm was still a technological novelty in the 1950s; but, as its use increased, so did criticism of it. Microfilm was hotly debated in both the American Archivist and Canadian Archivist. ${ }^{29}$ Opponents argued that it was still an unproven preservation medium, requiring excessive financial investment and staff time. Many were opposed to providing machine-mediated access that would be susceptible to malfunction. Opponents also expressed concern that microfilming entire collections weakened the role of archivists as gatekeepers. Some critics argued that users preferred curated access that provided contextualized archival information rather than wading through reels of microfilm.

Like manuscript publishing, microfilm was supported by the National Historic Publications and Records Commission (NHPRC) grants beginning in the 1960s. ${ }^{30}$ In fact, the NHPRC often funded dual microfilm-manuscript publishing projects and continues to do so. ${ }^{31}$ The assumption that superior technologies always replace older, less efficient technologies does not hold true for microfilm and manuscript publishing, which flourished side by side for decades. Online digital collections have largely supplanted both since the 1990s; but whereas microfilm and manuscript publishing historically represented two diametrically opposed approaches to access, digital platforms can support both curated and uncurated access. Promotional tools, such as online exhibits, blogs, and social media, increasingly serve as vehicles for curated access, while digital content management systems provide uncurated access.

29. For a sample of the often lively debate over microfilm, see Jerry McDonald, "The Case against Microfilming," American Archivist 20.4 (Oct, 1957): 245-56; Ernest P. Taubes, "The Future of Microfilming," American Archivist 21.2 (Apr. 1958): 153-58; Leon deValinger, Jr., "A Microfilmer Replies," American Archivist 21.3 (July 1958): 305-10; Margaret M. Weis, "The Case for Microfilming," American Archivist 22.1 (Jan. 1959): 15-24; Sam Kula, "The Preparation of Finding Aids for Manuscript Material on Microfilm," The Canadian Archivist 2 (1964) 3-10. For an example of a controversial, sometimes polemical, critique of library microfilm projects from an outsider's perspective, see Nicholas Baker, Double Fold: Libraries and the Assault on Paper (New York: Random House, 2001).

30. Thomas E. Jeffrey. "Microform Editions of Documentary Collections: Where Do We Stand? And Where Do We Go from Here?" Newsletter of the Association for Documentary Editing 4 (Sept. 1982): 1.

31. See "What We Fund," NHPRC, available online at www.archives.gov/nhprc/apply/eligibility. html\#fund [accessed 17 September 2015]. 
Documentary editing took a leading role in the transition to digital access technologies. The earliest coordinated effort to merge text and metadata in electronic format was the Text Encoding Initiative (TEI), a standards consortium created following the joint meeting of the Association for Computers and the Humanities and the Association for Literary and Linguistic Computing in November 1987. The primary goal of the TEI was to construct parameters for transcription and exchange of historical and humanities texts in the rapidly shifting digital environment that preceded the World Wide Web. ${ }^{32}$ Though TEI would never see widespread adoption by archivists in the United States, its platform for the digital representation and exchange of texts included many of the objectives that would later be addressed by archival standards such as Encoded Archival Description (EAD), ${ }^{33}$ Metadata Encoding and Transmission Standard (METS), Metadata Object Description Schema (MODS), and the Open Archival Information System (OAIS). TEI's historic significance lies in its ambitious vision, rather than its material success. TEI's failure to become an archival standard largely stemmed from its origin in a user community focused on scholarly editions of texts, and its limited incorporation of other formats, such as photographs.

In the 1990s and 2000s, a number of technological innovations converged, marking a singular development in the history of access. Technologies such as microfilm and union catalogs enhanced existing models of access, rather than creating new ones. However, with the development of standards for image, text, and video exchange, combined with Optical Character Recognition (OCR), it became possible to make digital facsimiles and metadata searchable and accessible online, fulfilling David Bearman's prediction that archival access would eventually combine catalog records and digital surrogates. Generalized standards such as EAD, METS, Dublin Core, MODS, and OAIS facilitated the electronic exchange of digital objects, including an increasingly wide range of types and formats. These standards laid the groundwork for facilitating the description and exchange of metadata and digital objects across multiple repositories. They also opened the door to new research methods, such as text mining and quantitative analysis of data and metadata.

The development and adoption of standards for the exchange of digital objects has transformed the special collections reference model. Researchers now have the ability to search metadata and textual content of digital objects simultaneously, some-

32. The TEI was ambitious and prescient in its scope, outlining a broad set of goals in its "Poughkeepsie Principles" that included format guidelines for data interchange in humanities research, including encoding conventions for the representation, documentation, interpretation, and analysis of texts in machine readable form. See James Cummings, "The Text Encoding Initiative and the Study of Literature," in A Companion to Digital Literary Studies, eds. Ray Siemens and Susan Schreibman (Oxford: Blackwell, 2007), 452.

33. For a full history of EAD, see "Development of the Encoded Archival Description DTD," Library of Congress, available online at www.loc.gov/ead/eaddev.html [accessed 17 September 2015]. 
times across multiple collections and repositories. Furthermore, access to primary sources is no longer limited to graduate students and scholars. Undergraduates, $\mathrm{K}-12$ students, and the general public have become significant user groups. This flattening of the archival world lessens the importance of individual repositories and collections, at least from the researcher's perspective. For many researchers, the location of archival material matters less than the level of digital access. Digital access has eased tensions between curated and uncurated approaches, and between preservation and access. However, in an environment where users expect digital access to all materials at all times, new concerns have arisen as institutions struggle to allocate limited resources for digitization. An additional consideration is the fact that not everything can be legally digitized, and there are many ethical questions surrounding access to sensitive digitized and born-digital material. Who has the right to determine access and to what degree? Finally, while more and more content is online, those who lack high-speed Internet access and those who primarily use the Internet through mobile devices may be limited in their access to digitized and born-digital primary sources. These issues are likely to be the driving forces behind future developments in special collection access technologies.

\section{Promotional Tools}

Promotion is an essential step in connecting potential users, through serendipitous happenstance, to collections and items that they did not realize existed. The ability to take advantage of new technologies, including the proliferation of personal computers and the Internet, has brought promotion to the forefront of the special collections profession. Growing interest in promotion may be a result of the success of discovery tools and digital facsimiles in reducing researchers' reliance on librarians and archivists to help them find materials. Additionally, new approaches to minimal processing of archival collections may be shifting the workloads of archival professionals and allowing them time to prioritize promotion. The democratization of access has had the side effect of dehumanizing the research process, and promotional tools offer a venue for providing users with a curated interpretation of materials that benefits from librarians' and archivists' unique skill sets and knowledge.

Although promotion and outreach have likely been part of archival practice for decades, there is little historical literature documenting them. In a session at the 2011 SAA Annual Meeting, ${ }^{34}$ George Bain posited that outreach was not a priority for early archivists because they were fully occupied with the deluge of records created during World War II, particularly archivists at federal repositories, who made up the

34. George Bain, John Fleckner, Kathy Marquis, and Mary Pugh, "Reference, Access, and Outreach: An Evolved Landscape, 1936-2011 (Session 406),” American Archivist 74, supplement 1 (Jan. 2011): 33-34. 
bulk of early SAA members. Limited coverage of promotion may also have been due to the local limitations and idiosyncrasies of those activities. In his presentation, Bain focuses on the "who we are" and "what we do" aspect of outreach, providing an historical overview of the propagation of outreach in the profession, touching upon promotional events such as Archives Month and National History Day, but he does not discuss the specific activities or tools used to accomplish outreach.

Desktop publishing was a new development in the late 1980s. With the introduction of PageMaker in 1985, repositories would have had the option of self-publishing brochures and newsletters for their donors and researchers. However, the coverage of desktop publishing in archival literature as a promotional technology is virtually nonexistent. The same is true of departmental websites. The mid-1990s brought the introduction of the first web browsers, ${ }^{35}$ and corporate and organizational websites were mainstream by the late $1990 \mathrm{~s}$. In one of the few articles published on websites of special collection repositories, Mark Shelstad concludes that websites' usefulness as a marketing tool was self-evident, so his case study focused on navigational structure and content. ${ }^{36}$

The late 1990s also saw the advent of blogs. Requiring minimal technical expertise, blogs allowed authors to easily share posts on the Internet and encouraged a social interaction between author and audience. ${ }^{37}$ In her seminal work on the archival potential of blogs, Catherine O'Sullivan states that "the Internet space that on-line diaries occupy is one of the few places today where a level ground for publishing actually exists." ${ }^{38}$ Today, social media is endemic, "[consisting] of a group of Internet-based applications that build on the ideological and technological foundations of Web 2.0, and that allow the creation and exchange of user-generated content." ${ }^{39}$ According to a 2012 report from the Pew Research Center, "half the adults and three-quarters of the teenagers in America use social networking sites. ${ }^{40}$ In light of these numbers, a repository would be hard-pressed to justify

35. Mitch Betts, "The Story So Far: How the Web Crossed the Atlantic and Became More Than a Plaything for European Physicists," ComputerWorld (Aug. 19, 2002), available online at www.computerworld.com/article/2576978/enterprise-applications/the-story-so-far.html [accessed 14 September 2015].

36. Mark Shelstad, "Content Matters: Analysis of a Website Redesign," OCLC Systems \& Services: International Digital Library Perspectives 12.3 (2005): 209-25.

37. "It's the Links, Stupid," The Economist 8474 (Apr. 22, 2006): 121.

38. Todd Levin, "Dear Diary," Salon.com, available online at http:/ / salon.com/tech/feature/1999/12/10/diaryland.html [accessed 21 September 2015]; Catherine O’Sullivan, "On-line Diaries, and the Future Loss to Archives; or, Blogs and the Blogging Bloggers Who Blog Them," American Archivist 68.1 (Spring/Summer 2005): 65.

39. Andreas M. Kaplan and Michael Haenlein, "Users of the World, Unite! The Challenges and Opportunities of Social Media," Business Horizons 53, no. 1 (2010): 61, available online at www.sciencedirect.com/science/article/pii/S0007681309001232 [accessed 14 September 2015].

40. Keith Hampton, Lauren Sessions Goulet, Cameron Marlow, and Lee Rainie, "Why Most Facebook Users Get More than They Give: Summary of Findings," Pew Internet \& American Life Project (Feb. 3, 2012), available online at www.pewinternet.org/2012/02/03/why-most-facebook-users-get-morethan-they-give [accessed 14 September 2015]. 
not participating in social media. Furthermore, blogs and social networking may be able to provide small repositories with the means to adopt a greater online presence than previously possible. However, it should be noted that libraries and archives were not early adopters of social media. In fact, a survey conducted in 2011 found that there was not widespread adoption of social media manifestations (blogs, Facebook, and Twitter) by special collections until 2009. ${ }^{41}$ This happened to also be the year the Society of American Archivists published The Interactive Archivist, which featured 13 case studies demonstrating how to develop a blog, Facebook page, and Twitter account, as well as explaining the advantages and disadvantages of each. ${ }^{42}$

The goal of all access technologies, including promotional tools, is to unite users with appropriate material. Through tools like desktop publishing, online newsletters, department websites, blogs, and social networking services, special collections repositories are able to overcome the structural and content limitations of discovery tools and better match users with holdings. Social media also allows archivists and librarians to target specific user groups and communicate with them in their own language. When archives avoid the use of archival jargon, social media offers the opportunity for colloquial communication with users that counterbalances the limitations of standardized vocabularies. For example, a collection that is primarily categorized as family history might well be a fruitful site for exploring gender performance. By their very nature, promotional tools provide only snapshots of materials and are not able to convey the entirety of a document, artifact, or collection, let alone a complete picture of a repository's holdings. This can, however, be partly overcome by incorporating links to discovery tools or digital reproductions. For example, linking to finding aids from Wikipedia offers an access point to potential users who would not seek out library catalogs. Special collections no longer receive input only from onsite researchers, but have access to the thoughts and opinions of a much wider universe of users through social media, as well as statistics generated by digital collection use. Kate Theimer defines Archives 2.0 as "an approach to archival practice that promotes openness and flexibility." By taking on the role of facilitator, rather than gatekeeper, archivists can use social media tools to "invite user contributions and participation in describing, commenting, and re-using collections, creating so-called collaborative archives." ${ }^{\prime 3}$

\footnotetext{
41. Heyliger, Sean, Nikki Thomas, and Juli McCloone. "Making Connections: A Survey of Special Collections' Social Media Outreach.” American Archivist Fall/Winter, 2013.

42. "The Interactive Archivist: Case Studies in Utilizing Web 2.0 to Improve the Archival Experience," eds. J. Gordon Daines III and Cory L. Nimer, Society of American Archivists, available online at http:/ / interactivearchivist.archivists.org [accessed 30 August 2012].

43. Kate Theimer, "What Is the Meaning of Archives 2.0?" American Archivist 74 (Spring/Summer 2011): 60 .
} 


\section{"Mega-choice": Where Do We Go from Here?}

The development of discovery, reproduction, and promotion technologies over the past two centuries demonstrates that there has been a universal trend toward standardizing special collections practice, description, and integration. Standardization and integration have empowered users to conduct their research with less intervention by repository staff. However, this very freedom has made users vulnerable to illusions of transparency and completeness - that descriptive records offer ideologically neutral descriptions and that all available materials are described and accessible through online searching. Thus, to mitigate the negative effects of the success of discovery and reproduction tools, the profession has become progressively concerned with the use of promotional tools to educate users, bring their attention to materials that might otherwise be overlooked, and reintroduce elements of personal connection and shared passion into the research process.

Although the goals remain distinct, all three types of access tools-discovery, reproduction, and promotional—now take place in online platforms, which are increasingly integrated. For example, a post on a repository blog might link to a catalog record and a digitized version of the materials discussed in the post. Both the catalog record and digital facsimile may offer users the opportunity to tag, comment, or further repurpose the information by sharing or downloading the item and its metadata. Today, access technologies not only affect how and where researchers find and use information, but how they analyze it and the kinds of analysis they can do. Digital humanities projects using text and data mining, geographic information systems (GIS), cultural analytics, and related strategies make use of special collections materials in ways that would have been impossible in the research environment of 50 years ago. ${ }^{44}$ As discovery tools improve and as more metadata and digitized collections are made available in standardized formats in databases and content aggregators, users are able to collate and synergize information in radically new ways.

This article leads to several questions that will be key to discussions of access over the next few years. How will the library profession as a whole overcome the limitations of current search interfaces to make them faster, more transparent, and more easily visible to a wider audience, while also protecting users' privacy? In a related vein, how effectively will the new Resource Description and Access (RDA) standards address the limitations of records created under earlier cataloging standards? Is social metadata and tagging a dead end, or can the library community encourage the development of vibrant conversations within catalogs and digital collections?

44. Josh Honnand and Geoff Morse, "Digital Humanities (101)," $d h+l i b, A C R L$, available online at http:/ /acrl.ala.org/dh/2013/03/27/digital-humanities-101 [accessed 7 October 2015]. 
Returning to questions of privacy, as the mass of digitized and born-digital material grows, how will future professionals grapple with legal and ethical questions of providing online access at scale? Will the trend of standardization expand to encompass profession-wide guidelines, or will these questions remain institutionallevel decisions? Finally, as repositories struggle to meet the needs of an ever-growing audience with fewer staff and resources, how will the promotional activities that ensure a human dimension to the research process be maintained?

Writing on the cusp of the digital revolution in the late 1980s, Canadian archivist Hugh Taylor described access points for archival information as "pipes through which the information flows towards the user." 45 He expressed concern that the increasing number of "informational pipes" and the environment of "mega-choice" in his time would overwhelm users and believed that "finding a way through may be a matter of finding our way back." ${ }^{46}$ Taylor advocated a return to the conditions of a previous era, where understanding and knowledge took the place of decontextualized data and information bytes. However, moving backward is never a practical possibility and, in fact, will only appear desirable to those whose social and academic background placed them in a privileged relationship with the earlier network of technologies and practices. Few would look longingly back to the age before digital technology, but Taylor may be correct that we-as archivists and librarians-must look at the successes and shortcomings of previous access technologies to gain a better understanding of how technology mediates user access to archival information and to better use technology to guide users through a world of ever-growing "mega-choice."

45. Hugh Taylor, “Transformation in the Archives: Technological Adjustment or Paradigm Shift?" Archivaria 25 (Winter 1987-1988): 25.

46. Ibid., 13 .

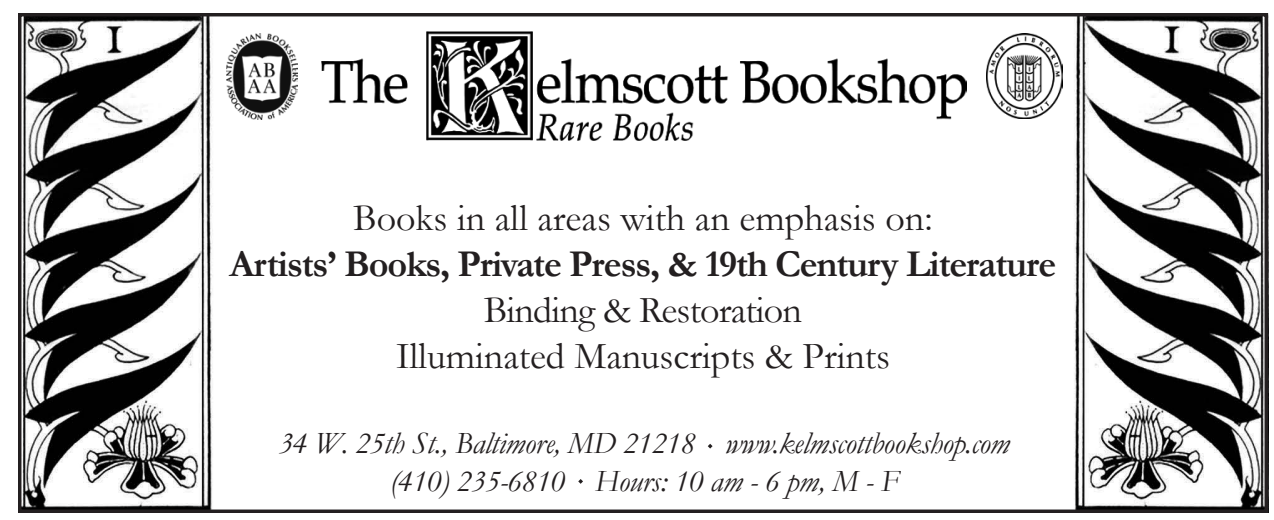

